Macagno, Lorenzo: “¿Buenos portugueses? Una diáspora china en el Mozambique colonial”; en REA, No XXIII, 2017; Escuela de Antropología - FHUMYAR - UNR; pp. 15-37.

\title{
¿Buenos portugueses? Una diáspora china en el Mozambique colonial
}

\author{
Lorenzo Macagno \\ Departamento de Antropologia \\ Universidade Federal do Paraná, Brasil \\ lorenzomacagno@hotmail.com
}

\section{Resumen}

A partir del siglo XIX, una creciente inmigración china comenzó a instalarse en algunos países africanos. En el caso de Mozambique - colonizado por Portugal-una de las minorías más notables provenía de la provincia de Guangdong, en el sur de China. En la década de 1950, estas familias de origen chino (más específicamente, cantonés) ya estaban integradas en la sociedad colonial de manera exitosa. A los ojos de los administradores coloniales, los miembros de esta importante minoría fueron vistos como "buenos portugueses". El artículo trata sobre la gradual incorporación de la comunidad china de Mozambique a la sociedad colonial. Cuando en 1975 llega la independencia del país, estos "buenos portugueses" comienzan a ser vistos, por los africanos nacionalistas como cómplices del colonialismo. Debido a las crecientes hostilidades deben abandonar Mozambique y "elegir" el camino de la diáspora. La gran mayoría de la comunidad chino-cantonesa de Mozambique se instaló en Brasil, sobre todo en la ciudad de Curitiba. A partir de una investigación de campo realizada entre las familias de la diáspora, este artículo analiza, también, la singularidad de sus trayectorias, así como las "narrativas de decepción" que giran en torno a su emigración de Mozambique.

\section{Palabras clave:}

Mozambique - chinos - colonialismo portugués - diáspora - trayectorias 
MACAGNO, Lorenzo - “¿Buenos portugueses? Una diáspora china...”

\title{
Good Portuguese? The Chinese Diaspora in Colonial Mozambique
}

\begin{abstract}
In the second half of the 19th century the growing Chinese inmigration arrive in East and South Africa. In the case of Mozambique - colonized by Portugal- one of the most important group of these minority came from the province of Guangdong, in the South of China. Around 1950 those families were successfully integrated into the colonial society. To the eyes of the colonial administrators, the members of this important minority became "good Portuguese". This article reconstructs the incorporation of the Chinese community of Mozambique into the Portuguese colonial society. Since the independence of Mozambique in 1975 those "good Portuguese" were suspected of complicity with the colonial regime. Due a growing hostility towards them, they must abandon Mozanbique and "chose" the route of the diaspora. They mainly settled in Brazil, particularly in Curitiba city in the State of Paraná. This article also analizes through fieldwork the singularity of their trajectories as well as "disappointment narratives" concerning their emigration from Mozambique.
\end{abstract}

Keywords:

Mozambique - Chinese - Portuguese colonialism - diaspora - trajectories

\section{Introducción}

El presente artículo constituye el resultado parcial de un trabajo de campo multi-situado realizado entre Portugal, Brasil y Mozambique. La primera vez que visité Mozambique en 1996, fue para realizar una investigación de doctorado cuyos objetivos eran indagar sobre las consecuencias contemporáneas de la construcción jurídica del "asimilado". Durante la presencia colonial portuguesa en Mozambique, la categoría de "asimilado" se refería a aquél africano que conseguía abandonar sus valores socio-culturales para incorporar los diacríticos civilizacionales de Portugal. Sin embargo, la sociedad del Mozambique colonial -a pesar de la grosera formación etnográfica de los administradores portuguesesno se dividía, binariamente, entre africanos asimilados, por un lado, e indígenas portadores de "usos y costumbres", por otro. La complejidad 
étnico-social ofrecía un caleidoscopio de formas mutables que desafiaban el normativismo jurídico del paradigma asimilacionista portugués. En efecto, además de los múltiples grupos étnicos que daban forma a ese mundo complejo había, en la sociedad colonial, otros grupos con los cuales la administración portuguesa debía lidiar: la presencia de súbditos indo-paquistaneses, inmigrantes provenientes de Goa, comerciantes musulmanes que transitaban por toda la región del Océano Índico y, también, comunidades de inmigrantes chinos, oriundos de la provincia de Guangdong que se instalaron, a partir de la segunda mitad del siglo XIX, en la ciudad mozambiqueña de Beira. Este artículo aborda, justamente, un fragmento de la experiencia diaspórica de este último grupo.

La pregunta que nos orienta nace del propio dilema asimilacionista portugués. ¿Cómo legislar en relación a grupos que ya traían, a los ojos de los administradores coloniales, un background civilizacional supuestamente milenario? ¿Qué lugar ambiguo ocuparon estas comunidades chinas en la sociedad colonial mozambiqueña? ¿Y qué consecuencias tuvo esa ambigüedad para el destino diaspórico de los chinos de Mozambique, considerados, además, ciudadanos portugueses?

La cronología de esta dispersión opera en tres momentos significativos: 1) La emigración del sur de China (Guangdong) para Mozambique en la segunda mitad del siglo XIX; 2) La creciente y bien sucedida "entrada" de los chinos-cantoneses en la sociedad colonial: a partir, sobre todo, de 1940 y que alcanza su período de auge en la década de 1960 cuando las comunidades chinas de la ciudad de Beira comienzan a ser retratadas, en los diarios de la época, como "buenos portugueses"; 3) El momento de la independencia de Mozambique, en 1975, cuando la complicidad de estos "buenos portugueses" con el régimen colonial es puesta en evidencia por los portavoces de los grupos nacionalistas, sobre todo por parte de los representantes del FRELIMO (Frente de Liberación de Mozambique). Este tercer momento es decisivo: las familias chinas de Beira deben -con sus pasaportes portugueses- reemprender el camino de la diáspora.

El escenario de este "drama social" (en el sentido turneriano) se eri- 
MACAGNo, Lorenzo - ¿Buenos portugueses? Una diáspora china...”

ge bajo el fracaso inminente de la construcción de un "Gran Portugal", es decir, de una quimera expansionista que la dictadura salazarista (19301974) ${ }^{1}$ se empecinó en imaginar. En efecto, las comunidades chinas de Mozambique, estaban llamadas a ser parte de ese mandato Imperial: el de un Portugal "multi-racial" y multi-étnico en el cual las Provincias Ultramarinas (entre ellas Mozambique) eran consideradas como simples extensiones “espirituales” de la Metrópoli.

Debido a que este trabajo nace, sobre todo, del imperativo etnográfico de capturar, por así decir, la experiencia de una dispersión muy puntual y específica -la de los chino-portugueses de Mozambique- me limitaré, para usar la conocida formula de Pierre Bourdieu, a traer para los lectores las "cosas" de la lógica, sin prejuicio de que ellas mismas puedan insinuar la "lógica" de un drama que es, al mismo tiempo, político, jurídico y experiencial. Si el mandato primordial de la antropología, que aún enseñamos a los estudiantes iniciantes, es el de "captar el punto de vista del nativo": ¿Qué acontece cuando ese "nativo" parece haber sido más o menos simpático a una causa colonial?

Justamente, a los ojos de la administración colonial portuguesa, este grupo fue retratado -sobre todo en los periódicos locales de la época (década de 1950)- como "simpáticos chinos". Posiblemente el caso de los "luso-chinos" desafíe algunos de los lugares comunes antropológicos e incomode nuestra buena conciencia. Sin embargo, nuestro objetivo, más allá de cualquier dilema moral, es captar una experiencia diaspórica que asume múltiples significados y trayectorias. Por eso, buscamos inspiración en las etnografías "experimentales" focalizadas, también, en grupos que fueron históricamente refractarios al interés del mainstream antropológico: pensamos, por ejemplo, en el trabajo de Vincent Crapanzano, sobre los "afrikáners" (el "antipático" grupo de Boers que adhirió

1. António de Oliveira Salazar (1989-1970) fue el líder principal del llamado "Estado Novo" en Portugal. Gobernó el país entre 1932 y 1968.

2. El sufijo "luso", proviene de "lusitano", término que se usa genéricamente para denominar a los portugueses. 
al apartheid) de Sudáfrica. Su última etnografía, sobre los Harkis (soldados argelinos que, durante la guerra de independencia de Argelia colaboraron con el ejército francés) se sitúa, también, en ese lugar incómodo -aunque necesario- de búsqueda de comprensión de una experiencia de dislocamiento de un grupo otrora simpático a la causa colonial (Crapanzano, 1986; 2011).

\section{De Guangdong a Mozambique}

Los primeros contingentes de chinos, oriundos de Guangdong, que llegaron a Mozambique en la segunda mitad del siglo XIX estuvieron mayoritariamente compuestos por pequeños artesanos y carpinteros, otros se dedicaron, también, a la pesca y a la horticultura. A lo largo de décadas, numerosas compañías de capital británico, tales como South African Timbu, East African Shipping, Allen Wack y The Beira Boating Company se instalaron en la región, incentivadas por la existencia de un corredor económico y comercial entre Rodesia (actual Zimbabue) y Beira, cuyo puerto constituía la única salida al mar para el país vecino. Muchos de ellos, así como sus descendientes, se emplearon en estas filiales ${ }^{3}$. Los hijos de aquellos pioneros, ya nacidos en Mozambique, se destacaron como comerciantes, dueños de restaurantes y despachos de bebidas para los africanos. Algunos se emplearon como pequeños funcionarios de la administración colonial, en el puerto y en la aduana. Posteriormente, los más exitosos, consiguieron hacer fortuna actuando como empresarios y constructores.

Muchas de las familias que llegaron a Mozambique- tanto a la ciudad de Beira como a Lourenço Marques- no cortaron sus vínculos con Guangdong o con China en general. Algunos de los hijos y nietos de esa primera generación eran enviados a estudiar o a pasar temporadas en Macau y Hong Kong con familiares que no habían podido emigrar a

3. Estas compañías brindaban bastante estabilidad económica a los funcionarios chinos, se les pagaba generalmente en escudos, libras esterlinas y en oro. (Información personal de A. Y., New York, 28/05/2010). 
MACAGNO, Lorenzo - “¿Buenos portugueses? Una diáspora china...”

Mozambique. Llegada la década del 30, los violentos ataques japoneses a las aldeas de Guangdong, durante la guerra chino-japonesa, motivaron que aquellos que esperaban retornar a China cambiasen de idea. Entonces, África pasó a ser un destino definitivo.

Cabe recordar que la historia de la provincia de Guangdong está íntimamente relacionada con el tortuoso proceso de construcción del nacionalismo chino que, a su vez, tuvo profundas repercusiones entre las comunidades chinas de Ultramar (Pan, 1998).

En 1895, después de formar la Sociedade para a Refundação da China, Sun Yat Sen decide que la provincia de Guangdong sería el punto de partida de las actividades revolucionarias. El papel que las asociaciones chinas tuvieron en el exterior fue fundamental en la promoción de la causa republicana vinculada a Kuomintang. La principal de estas asociaciones - con filiales en varios continentes- era la Chee Kung Tong, cuyos códigos y prácticas asociativas respondían a los principios de la masonería. Sus orígenes se remontan al siglo XVIII, cuando sus asociados pretendieron conspirar contra la dinastía Ching, vinculada a los Manchu. A partir del siglo XIX, las filiales de Chee Kung Tong se extendían por todo el Sudeste Asiático, América, Canadá, Australia, África del Sur e inclusive Mozambique.

\section{La construcción de un ethos:}

\section{¿buenos portugueses o buenos chinos?}

Entre 1950 y 1960, los diarios Notícias da Beira e Diário de Moçambique comienzan a retratar, cada vez con más atención, los acontecimientos relacionados a la comunidad china: eventos deportivos, reuniones con autoridades locales, festividades, así como entrevistas y obituarios. Estas notas periodísticas estaban atravesadas por un tono celebratorio y adulador. Al aprender a ocupar "su lugar" y al colaborar con la sociedad beirense estos chinos se tornarían, a los ojos de sus aduladores, "buenos portugueses" y "simpáticos" ciudadanos.

El contexto de elaboración de esas narrativas periodísticas coincide con el momento en que Portugal pretendía mostrar a la comunidad inter- 
nacional una singular vocación ultramarina. Esta posición se radicaliza cuando frente a las presiones descolonizadoras externas Portugal esgrime el argumento de la supuesta existencia de una conexión emocional irreversible entre la Metrópoli y sus colonias. Se trataba de una especie de "política colonial de los sentimientos" que abrevaba con entusiasmo de las fuentes lusotropicalistas creadas por Gilberto Freyre: "Somos pobres materialmente pero ricos de espíritu" o "Somos un país pequeño, pero nuestro corazón es grande", rezaban los slogans preferidos de la época. En gran medida esta dimensión de emocionalidad permite abordar de forma singular el proceso de construcción del Otro como alguien que es al mismo tiempo "próximo-distante" y virtual miembro de la "familia" lusa. En el caso de los chinos de Beira, su talento para ejercer el papel de "buenos portugueses" residía también en otros dos buenos atributos igualmente valiosos para la administración colonial. En primer lugar, se trataba de una comunidad que descendía de los viejos opositores republicanos, más tarde contrarios al régimen de Mao Tse Tung. De este modo, se situaban en las antípodas de la "amenaza comunista". En segundo lugar, el habitus de los chinos beirenses -y su ethos siempre orientado a la ascensión social y económica- se adaptó sin inconvenientes a las embestidas modernizadoras de la administración portuguesa durante ese período. Al mismo tiempo, el ejercicio de esa modernidad no era contradictorio con la rememoración, en ciertas festividades públicas, de una herencia civilizacional milenaria, como por ejemplo en la conmemoración del Año Nuevo Chino que se realizaba en Beira. La evocación ritual de esa fecha, así como otras celebraciones, eran étnicamente inofensivas para las pretensiones asimiladoras de Portugal, ciertamente se trataba solamente de un "retorno" meramente festivo a China. No obstante, la incorporación simbólica de ese pasado no desentonaba con el ideal civilizatorio portugués, atravesado muchas veces por una admiración orientalista singular. Los dos universos "civilizatorios" lejos de anularse podían recíprocamente admirarse y reconocerse.

Mientras tanto, los casamientos y las redes de relaciones familiares y de parentesco siguieron un patrón "oficialmente" endogámico, lo cual en 
MACAGNO, Lorenzo - “¿Buenos portugueses? Una diáspora china...”

gran medida reforzó la reproducción de una etnicidad diferenciada. Sin embargo, los hombres que llegaron en los primeros contingentes, y que no tenían esposas chinas, se relacionaron con mujeres africanas, aunque sin reconocerlo públicamente. Esta dimensión de la inter-etnicidad y del mestizaje supuso dinámicas complejas. De hecho, hoy en día en Beira y alrededores es posible encontrar una población significativa de "mixtos" ya asentados de forma definitiva en el territorio africano (más evidente en Inhassoro). Obviamente, estos grupos no formaron parte de la diáspora. Eduardo Medeiros (2007), en uno de sus artículos pioneros, prefiere referirse a estas dinámicas apelando a categorías diferenciales tales como "chino-africanos", "afro-asiáticos" y "chino-asiáticos".

\section{Fin del colonialismo, comienzo de la diáspora}

"Jóvenes", “dispuestos", “conscientes", "pujantes" "prudentes", "buenos deportistas", "ordenados", "trabajadores", "disciplinados" y, sobre todo, "simpáticos". Estos adjetivos son los que aparecen con más frecuencia en las crónicas periodísticas de 1950 y 1960, los mismos funcionan como categorías de adulación y, por lo tanto, como formas clasificatorias y creadoras de sentido. La comunidad china de Beira cobró existencia a través de este sistema de adulación. El deporte fue para los cronistas de la época una especie de mapa en el cual era posible leer e interpretar el "carácter", el modo de ser, el ethos de los chinos. Esas narrativas de afinidad no se producían en un ambiente político neutro. Se trataba de un período en el cual Portugal radicalizaba su discurso "multiracialista", en un contexto donde eran crecientes las presiones internacionales instando a que Portugal ponga fin a su presencia colonial en las Provincias Ultramarinas. Al mismo tiempo era un período en el cual los jóvenes de la comunidad china adherían cada vez más a las causas de la Iglesia Católica local.

La diócesis católica de Beira fue creada en 1943. Como bien menciona Eduardo Medeiros ${ }^{4}$, en la década del 50 muchos jóvenes "luso-

4. MEDEIROS, E. (s. d.) "Crenças e práticas religiosas entre os sino-moçambi- 
chinos" se convirtieron al catolicismo. Uno de los factores que favoreció esas conversiones fue la acción que en el seno de la comunidad china desempeño el padre Serafin Bruno Amaral, vinculado al famoso obispo de Beira, Dom Sebastião Soares de Resende. Gracias a la intervención del padre Amaral se formó en 1954 la Asociación de la Juventud Católica China. El sacerdote también fue el organizador de la visita de Gilberto Freyre al Club Chino 5 . A estas acciones de "conversión" se suma a partir de 1955 el sacerdote jesuita Ferreira da Silva que había realizado parte de su noviciado en Canton (Medeiros, s.d.p.11) ${ }^{6}$.

La atribución de simpatía presente en las notas periodísticas antes mencionadas generó expectativas de reciprocidad inminente y, por ende, la posibilidad de que se construya un vínculo moral: el objeto adulado debe responder con un gesto firme e inequívoco para retribuir así la confianza que le fue depositada. Por lo tanto, las categorías de adulación crearon un compromiso virtual de "colaboración". En otras palabras, el metalenguaje involucrado en esta dinámica de potenciales afinidades podría ser traducido en el siguiente imperativo: "Usted puede ser uno de los nuestros, pero necesita demostrarlo". De hecho, a partir de los primeros acontecimientos independentistas contra Portugal en África, y en un momento en el cual la china maoísta - sobre todo en Angola ${ }^{7}$ - comienza

canos da Beira (Moçambique)", trabajo inédito.

5. Eric Morier-Genoud me facilitó esta información contenida en Diário pessoal del obispo de Beira, Dom Sebastião Soares de Resende.

6. Medeiros (s. d. p. 10) también destaca la influencia que algunas familias católicas portuguesas tenían sobre sus vecinos chinos, sobre todo en la Parroquia de S. João Baptista de Matacuane, creada el $1^{\circ}$ de setiembre de 1963 y administrada por la Compañía de Jesús, así como la Parroquia de Inmaculado Corazón de María, en Alto da Manga, dirigida, a partir de 1967, por los padres Combonianos. El colegio para niñas, sobre todo "mestizas", dirigido por las Franciscanas Misioneras de Calais, en la Parroquia de Alto da Manga, también fue bastante importante para la comunidad china.

7. Mario Pinto de Andrade, uno de los fundadores del MPLA, confirma ese apoyo en una entrevista dada a Michel Laban: “... Nuestro primer dinero no vino de Moscú, sino de China... Esa historia verdaderamente nunca fue contada. Lo digo algunas veces: lo dije en el libro sobre Cabral, lo dije también en los cursos en 
MACAGNO, Lorenzo - “¿Buenos portugueses? Una diáspora china...”

a apoyar esos movimientos, los chinos de Mozambique tuvieron que hacer un gesto inequívoco para evidenciar su vocación de "buenos portugueses". En aquel momento particularmente tenso y conflictivo para Portugal, la comunidad china de Beira no podía defraudar la confianza que se les había depositado en tanto buenos ciudadanos. Hubo un acontecimiento que provocó por parte de los chinos de Beira un gesto grandilocuente de apoyo a Portugal, fue cuando en 1961 se desató la lucha por la independencia de Angola. La muerte de algunos colonos civiles en ese país - provocada por los seguidores de Holden Roberto de la UPA(União para as Populações de Angola, y posterior fundador de FNLA (Frente Nacional de Liberação de Angola)- provocó creciente perturbación en todo el Ultramar. A partir de aquel incidente, en noviembre de 1961, un contingente de dirigentes del Club Atlético Chino, así como miembros de la Juventud Católica China de Beira deciden expresar públicamente su solidaridad con la "familia lusa" donando al gobernador de la provincia de Mania y Sofala, el Comandante Lopes Praça, un cheque destinado a las "víctimas del terrorismo" en Angola.

En la ceremonia de entrega del cheque -que fue noticiada en la primera página del diario Notícias da Beira- participaron varios miembros del Atlético Chino, su presidente Po Quin, así como el presidente de la Juventud China Católica de Beira, Hon Quin Chee. En esa ocasión, Chee, encargado de pronunciar el discurso delante del Gobernador, se refirió a Mozambique como un "pedazo de tierra portuguesa que también es nuestra" . Al final de la nota el diario informa que después de la ceremonia y de la entrega del cheque, "El Sr. Com. Lopes Praça, en una brillante

Mozambique a las jóvenes generaciones. Pero, de manera general, esto fue ocultado oficialmente: por causa del conflicto chino-soviético y por el hecho de que la Unión Soviética había ocupado el primer lugar en la ayuda directa" (Mário Pinto de Andrade. Uma entrevista dada a Michel Laban, Lisboa, Edições João Sá da Costa, p. 162-163.

8. "A Juventude Chinesa contribuiu com o seu auxílio para as vítimas do terrorismo em Angola. Os dirigentes do Atlêtico Chinês entregaram um cheque ao Governador de Manica e Sofala" Notícias da Beira, 25 de noviembre de 1961, p. 1. 
improvisación y muy sensibilizado, agradeció la iniciativa de los jóvenes chinos haciendo un gran elogio a la comunidad". Algunos meses antes la primera página del diario Notícias da Beira publicó una foto en la cual Po Quin, presidente del Atlético Chino, entregaba al gobernador de Manica y Sofala un distintivo del Club ${ }^{9}$. Se trataba de un gesto de bienvenida al nuevo gobernador que acababa de asumir su cargo.

Está claro que en el caso de los chinos mozambiqueños la atribución de simpatía podía funcionar también como un mecanismo que creaba en ese próximo-distante un compromiso de reciprocidad, obligando implícitamente a devolver la adulación y los elogios recibidos en la forma de una lealtad inquebrantable.

Pues bien, aquí, de forma peligrosamente seductora, los gestos que vehiculan el "reconocimiento" del Otro- y sus respectivas categorías de adulación- engloba otro metalenguaje: aquel que permite vislumbrar esa relación como una especie de 'double bind'. Ni enteramente portugueses ni enteramente chinos, cuando los nuevos vientos políticos cambiaron de dirección, tanto en la Metrópolis como en Ultramar, el único destino posible de los "luso-chinos" fue la diáspora.

Con la independencia de Mozambique y el movimiento 25 de abril en Portugal, los otrora aduladores de estos "buenos inquilinos" perdieron espacio en el nuevo escenario local e internacional. Sin la posibilidad de recurrir a un "padre" - o a una "madre"- que los cubriese de elogios, los chinos de Beira quedaron huérfanos. Los "simpáticos" amigos se transformaron de la noche a la mañana en amenazadores enemigos. No teniendo más lugar en el Mozambique independiente, muchos consiguieron instalarse en Portugal, Estados Unidos, Canadá y Australia. Sin embargo, la mayoría "escogió" Brasil y, más específicamente, la ciudad de Curitiba.

Entre finales de la década de 1960 y comienzos de los años 70, cuando la guerra entre el Frente de Liberación de Mozambique (FRELIMO) y el ejército portugués se hacía cada vez más intensa, los chinos de Beira,

9. Archivo Histórico de Mozambique, Notícias da Beira, 04 de febrero de 1961. 
MACAGNO, Lorenzo - “¿Buenos portugueses? Una diáspora china...”

en su carácter de ciudadanos de Portugal, comienzan a ser convocados al servicio militar para defender la bandera portuguesa.

Más tarde, con la derrota del ejército portugués, comienzan en Lusaka las negociaciones para la independencia. A partir de 1974, o sea durante el gobierno de transición, en tanto "propietarios" y sospechosos de complicidad con el régimen, los miembros de la comunidad china empiezan a sentir una hostilidad creciente. Con la independencia se incrementa la desconfianza: requisiciones nocturnas imprevistas y planificadas para buscar "mercancías escondidas", imposición de trabajos manuales en momentos arbitrariamente establecidos ("barrer la calle", "hacer pozos" eran, según el testimonio de los beirenses entrevistados en Curitiba, algunas de las tareas impuestas), bien como la obligación diaria de participar en los comicios de los Grupos Dinamizadores ${ }^{10}$.

En poco tiempo el FRELIMO se transformó en un Partido/estado, cuyo discurso de construcción de la nueva nación mozambiqueña pasó, a partir del III Congreso de 1977, por la adhesión al "marxismo-leninismo". La ley de nacionalizaciones ya estaba en vigencia. A pesar de que no existió una "expulsión" deliberada de la comunidad china, los cambios políticos mencionados hicieron que en poco tiempo los chinos pasasen de "propietarios" simpáticos a tornarse "inquilinos" indeseables. El abandono del país, que había comenzado entre 1973 y 1974, se intensifica después de la independencia. En algunos casos, la salida fue planeada con cierta anticipación gracias a contactos y redes de relaciones externas. Macao y Taiwán fueron algunos de los destinos iniciales; sin embargo, la mayoría se dirigió a Brasil, más específicamente a la ciudad de Curitiba ${ }^{11}$. Otros se "dispersaron" entre Portugal, Australia, Canadá y

10. Los Grupos Dinamizadores eran instancias de movilización y "esclarecimiento" (en fábricas, barrios etc.), cuya función era la de intermediar entre las orientaciones del Partido (FRELIMO) y las estructuras locales de organización de la sociedad.

11. Actualmente, según estadísticas que necesitan ser cotejadas, existen en Curitiba aproximadamente 100 familias de "chinos-mozambiqueños", lo que significa un total de cerca de 1000 individuos. En São Paulo, según testimonio de la propia 
Estados Unidos. Algunos por motivos puntuales, decidieron quedarse en Mozambique. En la ciudad de Beira, uno de los pocos que se quedaron, Chin Kock Saum- falleció en el año 2009. En Lourenço Marques (Maputo) probablemente permanecieron algunas familias más, entre ellas la vinculada a la famosa tienda "Ho Ling", localizada en el centro de la ciudad, cuyo responsable Yum Mah Wah además de comerciante es propietario de una pequeña machamba en Manhiça, cerca de Maputo. El famoso fotógrafo Kok Nam, es otro de los "chinos" que decidió asumir su "mozambiçanidad" y quedarse en África ${ }^{12}$.

A partir de la independencia de Mozambique se quiebra el tenue hilo de simpatía, aquel que tornara a los chinos "buenos portugueses". Las circunstancias políticas cambian. En el Portugal de la Revolución de los Claveles, la figura de los retornados, incluyendo los chinos "portugueses" oriundos de Mozambique genera incomodidad. En cambio, Brasil que entonces estaba gobernado por Ernesto Geisel, y en el marco de la implementación de políticas para la recepción de los retornados del África Portuguesa, les permitió el acceso a visas de estadía y autorización de trabajo.

¿Será tal vez que aquella dispersión que los chinos de Beira empiezan a experimentar desde 1975 se tornó una especie de profecía autocumplida, alimentada por la perpetua condición de próximos-distantes? Nunca completamente portugueses y nunca completamente chinos. Cuando comienza la independencia la posibilidad de un futuro mozambiqueño para los otrora "simpáticos" termina transformándose en una

comunidad, existen cerca de 50 familias.

12. Kok Nam (1939) es, tal vez, uno de los más ilustres mozambiqueños de descendencia china. Hijo de padres cantoneses, es, junto con Ricardo Rangel, uno de los más importantes fotógrafos del país. Kok Nam tiene una larga y rica trayectoria en el periodismo fotográfico (en medios mozambiqueños, como el Diário de Moçambique, A voz Africana, Revista Tempo, Savana). Tiene trabajos fotográficos publicados en diarios y revistas internacionales, tales como el New York Times, Time Magazine, Observer, The Independent, Expresso, entre otras publicaciones. Fue, también, el fotógrafo oficial de Samora Machel, primer presidente del Mozambique independiente. 
MACAGNo, Lorenzo - ¿Buenos portugueses? Una diáspora china...”

quimera: "ahora soy africano de origen chino, nacionalidad portuguesa, naturalizado brasileño", confesaba uno de mis interlocutores en Curitiba, mientras recordaba su pacata vida en la Beira de los años 60.

\section{De Mozambique a Brasil}

¿Por qué la mayoría de los chinos de Beira eligió Curitiba? En conversaciones y entrevistas que realicé con los beirenses, las respuestas me condujeron casi siempre a la figura de un "pionero": Chin Fai Lai. Él habría llegado a Brasil antes de 1975, más específicamente a la ciudad de Santos, donde se localiza el importante puerto, para visitar a su padre enfermo que trabajaba allí. El padre de Chin Fai Lai llegó a Santos directamente desde China, sin pasar por Mozambique. Después de heredar algún dinero de su padre fallecido y habiendo pasado por algunas ciudades de Brasil, Chee Fai Lai eligió finalmente Curitiba como lugar de residencia permanente.

Allí, abrió una "casa de espetinhos"13 en el centro de la ciudad. Cuando los chinos mozambiqueños buscando un lugar para instalarse comenzaron a accionar sus redes familiares externas, comenzó a correr la noticia de que Curitiba podría ser un buen destino. Esta narrativa del "pionero", a pesar de ser conveniente desde el "punto de vista del nativo", tiene sin embargo poco valor explicativo en términos de los condicionamientos estructurales y políticos que motivaron la elección. Otra de las respuestas que los beirenses acostumbran a elaborar tiene que ver con una especie de analogía socio-cultural entre las dos ciudades: entre la Beira del período tardo-colonial con sus hoteles, clubes, cafés y sus redes de sociabilidad y la Curitiba de los años 70 que se encontraba en plena expansión urbana. Según mis interlocutores habría muchas afinidades:

Prácticamente Curitiba se tornó una segunda ciudad de Beira. Aquí (en Curitiba) las personas se acercan entre sí. En Beira era así. Con-

13. Casa de "pinchos", brochettes. 
vivíamos con mucha armonía. Es un clima familiar, cuando hay una fiesta todos se juntan. Nos comunicamos mucho. Muchos (chinos de Beira) vienen aquí a visitarnos y les recuerda Beira. La Asociación Cultural China de Paraná, por ejemplo, fue construida en un 80 por ciento por beirenses (Curitiba, entrevista con K.V.Q., 17 de mayo de 2008)

Tal vez no sea una simple coincidencia el hecho de que los beirenses hayan elegido una de las ciudades menos "africanas" de Brasil. Al mismo tiempo, en su cualidad de ex-colonos en busca de un nuevo lugaruna especie de paraíso colonial perdido- es posible que esa búsqueda de compatibilidades, entre Beira y Curitiba, sea sólo una justificación elaborada a posteriori o, como diría Franz Boas, una simple "secondary explanation". Es probable que uno de los protagonistas clave en la elección de Curitiba haya sido el "hermano Cordeiro", conocida figura en los años 60 y 70 del colegio Marista de Beira, donde muchos chinos cursaron el Liceo.

Nacido en el sur de Brasil, después de haber realizado estudios maristas en la Escuela Normal Superior del Instituto Champagnat de Porto Alegre (Brasil) el hermano Armando Corbellini, más conocido en Beira con el nombre de "hermano Cordeiro", parte para África en 1948. Antes de llegar a Mozambique pasa un tiempo en Angola. En vísperas de la independencia de Mozambique se escapa por la frontera y logra llegar a Rodesia, donde toma un avión para Portugal. Los Hermanos Maristas de Portugal lo acogieron por un tiempo. En 1975 retorna a Brasil fijando residencia en Rio de Janeiro. Precisamente, uno de los trabajos que el "hermano Cordeiro" realiza en Rio de Janeiro consiste en recibir y ubicar en lugares adecuados a los recién llegados, sobre todo a aquellos venidos de Mozambique y Angola. Esas tareas se realizaban en el contexto del MAEP (Movimiento de Apoyo al Emigrante Portugués) creado en Rio de Janeiro en septiembre de $1975^{14}$. En aquel momento la ciudad

14. "Imigrantes tem ajuda no Rio" In: Jornal do Brasil, Rio de Janeiro, 29 de septiembre de 1975, p. 9. Ver, también, "Curriculum Vitae (Irmão Armando Corbelli- 
MACAGNo, Lorenzo - ¿Buenos portugueses? Una diáspora china...”

de Rio era el destino obligado de la mayoría de los "refugiados" de las ex colonias portuguesas: allí los recién llegados debían dejar en orden sus documentos antes de dispersarse por Brasil. El hermano Cordeiro -que era también piloto e instructor de paracaidismo- murió en Rio de Janeiro en junio de $1996^{15}$.

De todos modos, no es posible trazar un itinerario común a la experiencia de dispersión de los chinos beirenses. Aquellos cuyas familias poseían una red de relaciones culturales y comerciales que se extendían a lugares como Hong Kong, Taiwán o Singapur, consiguieron construir estrategias de salida y preparar con mayor planificación material sus vidas fuera de Mozambique. Y aquellos que en el momento de la dispersión no pudieron contar con la ayuda de parientes distantes tuvieron la colaboración de funcionarios consulares en sus respectivos países de destino, sobre todo en Brasil donde a partir del mencionado acuerdo con Portugal y del Movimiento de Apoyo al Emigrante Portugués (MAEP) en Rio de Janeiro, los "retornados" de las ex colonias, incluyendo los beirenses, tuvieron alguna protección diplomática. Como reconociera uno de ellos que hoy vive en Curitiba: "nosotros éramos refugiados de primera categoría”. Por lo tanto, aquellos que consiguieron salir en mejores condiciones pudieron llevar consigo algunas pertenencias personales, entre las cuales estaban sus fotografías familiares.

Las imágenes fotográficas que ilustraban las notas periodísticas sobre los chinos que aparecían en el Diário de Moçambique e Notícias da Beira no eran simples imágenes de carácter público. En verdad, surgían del propio universo familiar "íntimo" de los chinos de Beira y, si bien circularon en las notas a las cuales hicimos referencia son parte del acervo de memorias atesorado por la propia diáspora.

La fotografía, sus prácticas y representaciones, ocupan un lugar cen-

ni)" in: http://bernardetezanatta.blogspot.com/2009/10/curriculum-vitae-irmao-armando.html

15. Para más información consultar: http://familiazanattah.blogspot.com/2007/05/ vida-do-irmo-armando-corbellini.html 
tral en la constitución del hábitus cultural y de clase de los chinos de Beira. Hacia 1950 existían en la ciudad tres estudios fotográficos, cuyos propietarios pertenecían a esa comunidad: Foto Estudio, cuyo dueño era Eginwo Shung Chin; Foto Beira, cuyo dueño era Lee King Wing y, finalmente, Foto Central, que pertenecía a Kom Loom, quien emigró a Australia. En las instalaciones de estos estudios fue retratada gran parte de la vida social, deportiva y cultural de los chinos. Sin embargo, las fotografías guardadas por las familias esparcidas por el mundo no son solamente fotografías de estudio. En efecto, entre finales de la década de 1940 y comienzos de los años 50 muchos de ellos, que eran comerciantes exitosos, comenzaron a adquirir bienes de consumo como aparatos de radio, automóviles, toca-discos y máquinas fotográficas. De este modo, de a poco, las máquinas fotográficas fueron saliendo del estudio y entrando en la vida cotidiana. Fue posible entonces trasladarse y registrar las imágenes de la comunidad en innumerables momentos como picnics, bailes de la Escuela China, encuentros deportivos, paseos, salidas a la floresta para cazar o pescar, ceremonias oficiales, etc. Podría decirse que mi encuentro con la "diáspora chino-mozambiqueña" fue, en gran medida, un encuentro con imágenes fotográficas.

Algún tiempo después de las entrevistas y conversaciones que entre 2005 y 2009 había mantenido con los chinos beirenses en Curitiba retorné a Mozambique, recorriendo el camino inverso al que ellos habían realizado más de 30 años atrás. Actualmente, en el edificio de la antigua Escuela China funciona la escuela pública Agostinho Neto; el viejo predio del Club Chino es ahora la sede regional del ARPAC (Archivo del Patrimonio Cultural").

Más allá de la "experiencia" de recorrer los espacios acerca de los cuales tanto había oído hablar en Curitiba era necesario confirmar a través de las fuentes de la época el protagonismo que en las narrativas de la diáspora parecía auto evidente. En los diarios consultados en el Archivo Histórico de Mozambique encontré varias imágenes (poco claras, debido a la precaria calidad de las impresiones) las mismas que entre tantas otras ya había visto en Curitiba, pero en su versión clara, nítida y original. Si 
MACAGNo, Lorenzo - ¿Buenos portugueses? Una diáspora china...”

en Mozambique esas fotografías no eran más que historias depositadas en archivos, en Brasil, en cambio, formaban parte de un universo de referencias muy presente y poseían - parafraseando a Kopytoff (1986)- una "vida social". Esas imágenes constituyen, para la diáspora "beirense", un lugar de memorias, al cual es posible retornar indefinidamente.

El hecho de pertenecer al mismo tiempo a un registro público, los diarios, y privado, los álbumes de familia las torna testimonios inevitables del protagonismo que esos "buenos portugueses" tuvieron en la modernidad colonial de la Beira de los años 50 y 60 . Una modernidad que, dicho sea de paso, nunca se resignarían a abandonar.

\section{De proprietários simpáticos a incómodos inquilinos}

Algumas vezes, aos domingos, eu e Ching íamos de burra (era assim que chamávamos às nossas bicicletas) pelas margens do Chiveve, para ver os pescadores de mussopo e as vendedoras de marora. $\mathrm{O}$ pequeno chinês olhava o poente sobre as águas barrentas e seus olhos estreitos pareciam ver paisagens para além do oceano. Certo dia, ele me convidou para assistir a um desafio de basquetebol. Jogava o seu clube de peito, o Atlético Chinês. "Meu pai não me deixa dizer o nome do Clube em português", confessou. "E que outro nome tem o Clube?". É o Tung Hua Athletic Club"

Mia Couto, "A China dentro de nós"

Aunque algunos chino-beirenses -sobre todo los más viejos- después de salir de Mozambique consiguieron conservar la "nacionalidad" portuguesa, al momento de renovar sus pasaportes muchos de ellos encontraron una respuesta negativa en los consulados portugueses de los países donde se instalaron.

Ese hecho, que consumó su condición de portugueses ya no reconocidos, produjo las más variadas narrativas que circulan en el seno de la comunidad chino-beirense esparcidas por el mundo como mitos de decepción, contados y recontados una y mil veces. Entre esas narrativas, una de las más conocidas e ilustrativas se refiere a lo que podríamos de- 
nominar "el incidente del pasaporte". La causa que motivó tal incidente, ocurrido en el consulado de Portugal en Curitiba, habría sido la negación por parte de las autoridades consulares de conceder la renovación de la nacionalidad portuguesa a un beirense de la "diáspora". La reacción ante ese hecho habría sido inmediata: allí mismo en el mostrador de atención al público, este "africano, de origen chino, nacionalidad portuguesa, naturalizado brasilero", habría rasgado una a una las páginas de su viejo pasaporte portugués tirándolas en la cara de la funcionaria consular. El otrora "simpático" chino se había tornado ahora indeseable y agresivo.

El malestar emocional de estos chinos de Beira se reforzó por una aparente paradoja: muchos de ellos durante la guerra contra el FRELIMO habían defendido la bandera portuguesa. Tal como se lamentaba un beirense que hoy vive en Curitiba:

Quise renovar mi pasaporte portugués y fui rechazado. No me reconocieron como ciudadano portugués, esa fue una de las razones por la cual me naturalicé brasileño. No me reconocieron. Nací en Mozambique, luché en Mozambique, tuve que jurar la bandera portuguesa como hacen todos los portugueses antes de servir en el ejército y, aun así, no me reconocieron.

Los criterios objetivos y políticos de los agentes definidores de lo "nacional" cambian. Con este cambio, la subjetividad de aquellos actores, ahora blanco de nuevas definiciones identitarias, pasó de un confuso sentimiento de "afinidad" a una clara decisión "electiva": "ahora yo me siento más brasileño, por eso me naturalicé brasileño".

Con los cambios del período pos-colonial cambia también el estatuto de los chinos beirenses. La independencia de Mozambique y el fin de la dictadura en Portugal traen nuevos portavoces a un escenario ya pleno de sentimientos de desconfianza y aprehensión en relación a los otrora "buenos portugueses". Tales sentimientos alimentaban la idea de nación estaba en pleno cambio y precisaba urgentemente recomponerse en base a nuevas bases identitarias y políticas. Portugal atravesaba un momento liminar en el cual debía abandonar los designios de su vocación Imperial 
MACAGNO, Lorenzo - “¿Buenos portugueses? Una diáspora china...”

y comenzaba a vislumbrar los desafíos de su inminente futuro europeo. Como portadores de una ciudadanía ambigua, los chinos beirenses tuvieron también que reinventar su condición de (ex) portugueses nacidos en Mozambique. Mientras tanto, las memorias en torno del asociativismo y el deporte, así como las fotografías que evocan ese pasado constituyen para los "beirenses" de la diáspora, una fuente densa y significativa para la producción y reproducción de esa reinvención identitaria.

Entre finales de 1940 y comienzos de 1950 debido tal vez a las exigencias administrativas pautadas en un asimilacionismo creciente, el Thung Hua Atlhetic Club pasa a ser denominado Clube Atlético Chinés. Este desplazamiento metonímico no constituye un detalle menor. Tal como ilustra el epígrafe en el cual Mia Couto recuerda sus andanzas de infancia en Beira junto a su amigo chino, el "mundo portugués" y China eran dos universos entre los cuales la comunidad china y sus descendientes se debatían. Cuando la invitación para asumir el papel de "buenos portugueses" fue, por así decir, presentada de una forma explícita, los chinos de Beira no encontraron inconvenientes en aceptarla. Sin embargo, las circunstancias socio-políticas posteriores hicieron que no puedan asumir hasta las últimas consecuencias una "portuguesidad" que ahora les era negada con el mismo énfasis con que antes le había sido ofrecida. En cambio, tuvieron que adaptarse como diría Aihwa Ong (1999) a una "ciudadanía flexible".

Aquella tierra es de los "gajos"16, me decía al referirse a Mozambique un chino beirense que actualmente vive en Lisboa. Percibí que esa frase fue pronunciada con un tono de debilidad y confesión que incluía una densidad de significados concernientes a los problemas aquí tratados. Tal vez no sea obvio señalar que, en boca de mi interlocutor, la categoría "gajos" debe ser entendida como "africanos autóctonos".

16. En Portugal, y dependiendo del contexto socio-lingüístico, el término "gajo" puede vehiculizar una manera despectiva para referirse a una persona, algo parecido a lo que en el contexto rioplatense sucede con el término "tipo". De todos modos, la connotación puede no ser necesariamente negativa $\mathrm{y}$, por lo tanto, se trata de una categorización ambigua. 
Sin embargo, más allá de la lúcida y tranquilizadora aceptación de las circunstancias, la frase parecía estar englobando otro mensaje, esta vez más melancólico. Algo como una especie de fantasía de lo que no fue, pero podría haber sido, si "nuestros antepasados no hubiesen salido de China". Ahora, este retorno imaginario, y casi inconsciente, a un primordialismo perdido ofrece, paradojalmente, la clave para entender la propia dispersión beirense. Una dispersión que, vale recordar, reconoce dos momentos -y movimientos- clave: la salida de Guangdong hacia Mozambique y la salida de Mozambique para el mundo (sobre todo hacia Brasil). Es precisamente en ese segundo momento en que se cierra el círculo de una perturbadora profecía autocumplida. Si en el primer movimiento, de la llegada a Mozambique, la marca como "expatriados" parecía desvanecerse a medida que ingresaban en el seno de la familia portuguesa ahora, en el segundo movimiento, esa marca se torna en la "piel” de los chinos beirenses más indeleble que nunca.

\section{Conclusión}

A pesar de que la dispersión protagonizada por la comunidad china de Mozambique operó en un contexto de complejos cambios jurídicos (al fin y al cabo, era un nuevo Estado-nacional el que se estaba creando cuando tuvieron que salir de África) preferí poner entre paréntesis los aspectos normativistas-legales que impactaron en esta diáspora para, en cambio, privilegiar la dimensión experiencial.

Igualmente, antes que partir de definiciones más o menos arbitrarias acerca del concepto de diáspora y sus utilizaciones, opté por delinear algunos aspectos de un itinerario muy específico que puede ser, al mismo tiempo, iluminador de las paradojas y contradicciones del llamado asimilacionismo portugués. Es posible -y ese esfuerzo está fuera de los objetivos aquí delineados- que la propia noción de diáspora pueda ser repensada y problematizada a la luz del "caso" de la comunidad lusochina de Mozambique. Más allá de esa posibilidad, sin embargo, no debería ser un síntoma menor el hecho de que el concepto de diáspora comience a salir de su uso restricto y, por así decirlo "nativo" -cuyo 
MACAGNo, Lorenzo - ¿¿Buenos portugueses? Una diáspora china...”

referencial primordial sería el de la "diáspora judía"- y pase a ser utilizado, por primera vez en ciencias sociales, en 1965, para hacer referencia a, justamente, a los "chinos de ultramar" (Haines, 1965).

¿Será el ejemplo luso-chino un caso particular de una problemática más amplia -y extensamente trabajada (Trolliet, 1994; Ma Mung, 2000)subsumida bajo el concepto de "diáspora china”? ¿O se trata, simplemente, de un caso análogo al de otras "minorías asiáticas" oriundas de países africanos -como el de los indo-paquistaneses- que también se vieron forzadas al exilio durante el período de las independencias africanas? En este caso, es posible que la comparación se torne más fructífera respecto de otros asiáticos de Mozambique, como los ismaelitas, cuyos líderes consiguieron, antes de 1974, preparar y coordinar la salida del país de forma organizada (Melo, 2008; Pereira Leite \& Khouri, 2008).

Como diáspora en permanente mutación, los hijos y nietos de este grupo de luso-chinos dispersos por el mundo parecen, ahora, retornar al país de sus antepasados. Irónicamente o no, el "país de los antepasados" que hoy redescubren (para estudiar, para realizar sus negocios o, simplemente, visitar) es China, y no Mozambique. Para estos jóvenes que, prácticamente, ignoran el pasado africano de sus padres y abuelos, China se presenta como un terreno pleno de oportunidades. Ahora en otro contexto, el ethos de ascensión social que los tornó, en Mozambique, "buenos portugueses" convictos del ideario asimilacionista y del proyecto de modernización colonial, se reproduce bajo nuevas gramáticas.

\section{Bibliografía}

CRAPANZANO, V. (1986) Waiting. The Whites of South Africa. New York, Vintage Books.

(2011). The Harkis. The Wound that Never Heals. Chicago and London: University of Chicago Press.

HAINES, J. (1965) Chinese of the Diaspora. London: Edimburgh House Press for the World Council of Churches Commission on World Mission \& Evangelism. 
KOPYTOFF, I. (1986) "The Cultural Biography of Things", In: APPADURAI, A. (ed.) The social life of things. Commodities in cultural perspective. Cambridge University Press, 1986, pp. 66-91

MA MUNG, E. (2000) La diáspora chinoise. Géographie d'une migration. Paris: Collection GéOphrys.

MEDEIROS, E. (s/f) "Crenças e práticas religiosas entre os sino-moçambicanos da Beira (Moçambique), paper inédito, s. d.

-------- (2007) “Os sino-moçambicanos da Beira. Mestiçagens várias”, Caderno de Estudos Africanos, №13-14, pp. 155-187.

MELO, A. (2008) “A diáspora ismaelita - preparação e 'partida', vicências da migração dos anos 70" In: Joana Pereira Leite \& Nicole Khouri (eds.) Indiens du Mozambique et d'Afrique orientale. Lusotopie, Vol. XV (1).

ONG, A. (1999) Flexible Citizenship. The Cultural Logics of Transnationality. Durham \& London: Duke University Press.

PEREIRA LEITE, J. y N. KHOURI (comps.) (2008) Indiens du Mozambique et d'Afrique orientale. Lusotopie, Vol. XV (1).

TROLLIET, P. (1994) La diaspora chinoise. Paris: Presses Universitaires de France.

Recibido: 09/09/2017

Evaluado: $24 / 11 / 2017$

Versión final: 15/02/2018 